\title{
Plastic Sensor for Losartan Potassium Determination based on Ferroin and Ionic Liquid
}

\author{
Mohsen M. Zareh ${ }^{l,}$, Khlid ElGendy ${ }^{l}$, Anwar A. Wassel ${ }^{2}$, Ahmed Fathy ${ }^{l}$ and Yasser M. Abd Alkarem ${ }^{1}$ \\ ${ }^{1}$ Department of Chemistry, Faculty of Science, Zagazig University, 44519 Zagazig, Egypt. \\ ${ }^{2}$ NODCAR - National Organization for Drug Control and Research, Giza, Egypt. \\ "E-mail: mohsenzareh2@gmail.com, mmzareh@zu.edu.eg
}

doi: $10.20964 / 2018.02 .59$

Received: 2 October 2017/Accepted: 7 December 2017/ Published: 28 December 2017

In this study, a potentiometric sensor based on a plastic-membrane was introduced for the determination of losartan potassium in pharmaceutical formulations. The sensing element contained an ion-pair, which was synthesized by the interaction of losartan potassium and 1,10 phenanthroline monohydrate. The best membrane sensor response was obtained by a membrane composed of $30.6 \%$ PVC, $61.4 \% o$-NPOE, $7.5 \%$ ion-pair and $0.5 \%$ ionic liquid. The proposed method was successfully applied for the determination of losartan potassium in some formulations. The proposed sensor showed a linear dynamic range between $5.0 \times 10^{-5}$ and $1.0 \times 10^{-2} \mathrm{M}$ of losartan potassium with a Nernstian slope of $62.0 \pm 1.0 \mathrm{mV}$ per decade and a lower detection limit of $3.5 \times 10^{-5} \mathrm{M}$. It displayed a fast response time of about $10 \mathrm{~s}$, and a lifetime of about three weeks without any significant loss in its performance.

Keywords: Losartan potassium, potentiometric sensor, PVC membrane electrode, ion-pair.

\section{$\underline{\text { FULL TEXT }}$}

(C) 2018 The Authors. Published by ESG (www.electrochemsci.org). This article is an open access article distributed under the terms and conditions of the Creative Commons Attribution license (http://creativecommons.org/Licenses/by/4.0/). 